\title{
Sacrocolpopexy for Post Hysterectomy Vault Prolapse
}

\author{
Serge P. Marinkovic, Lisa M. Gillin and Christina M. Marinkovic \\ Department of Surgery/Division of Urology, \\ Female Pelvic Medicine and Reconstructive Surgery Specialist \\ St Joseph Hospital, Fort Wayne, Indiana, \\ USA
}

\section{Introduction}

Pelvic organ prolapse is most likely the result of one or more clinical entities that gradually assist in weakening the pelvic floor [Connell KA, 2011]. Direct childbirth trauma to the levator ani and surrounding pelvic floor tissue will decrease strength over the course of recurrent childbirth and time. These injuries compromise support of the pelvic floor and may deviate its apical $S_{3}$ horizontal orientation, while constant collagen and elastin remodelling may lead to further pelvic floor demise and upstage pelvic organ prolapse [Connell KA, 2011]. Over two hundred thousand women undergo the repair of pelvic organ prolapse in the United States every year. In fact, the cost for diagnosis and treatment exceeds two billion dollars annually [Subak LL, 2001]. A Kaiser Permanente retrospective, observational study surveyed 149,554 female patients over the age of twenty and estimated that the lifetime risk of undergoing a single surgery for pelvic organ prolapse or urinary incontinence by age eighty was eleven percent [Olsen 1997].

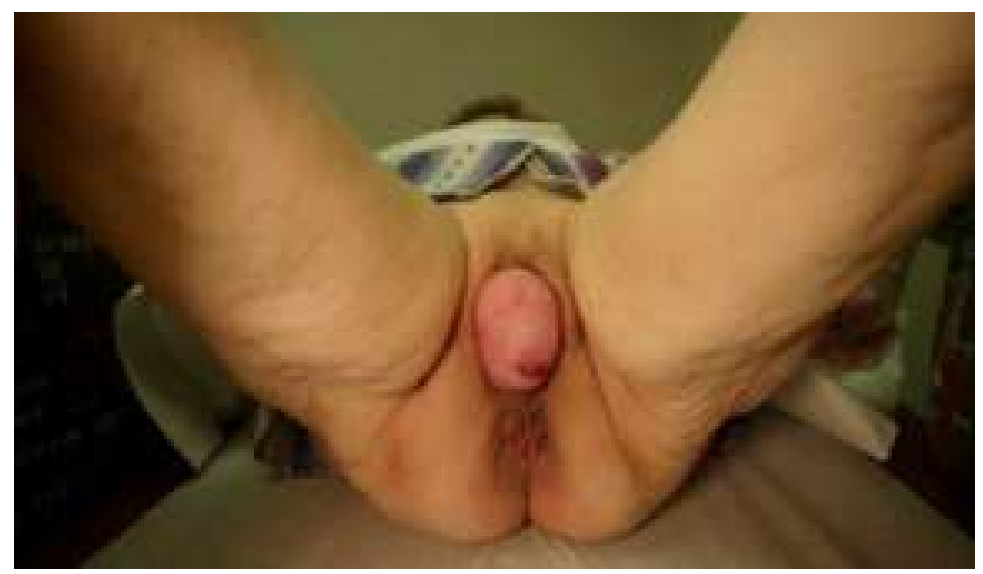

Fig. 1. Stage 4 Complete Procidentia. The cervix is the dimple in the middle of the photograph. Patient underwent a total hysterectomy and a double mesh, anterior and posterior polypropylene mesh [Scali Method, 1974] sacrocolpopexy. 
The need for recurrent pelvic organ prolapse surgery [within four years of prolapse surgery] has been estimated to be twenty-nine percent. Post-hysterectomy vault prolapse ranges from ten to forty percent and appears to have an equal occurrence regardless of whether the abdominal or vaginal approach is utilized [Maher C, 2010].

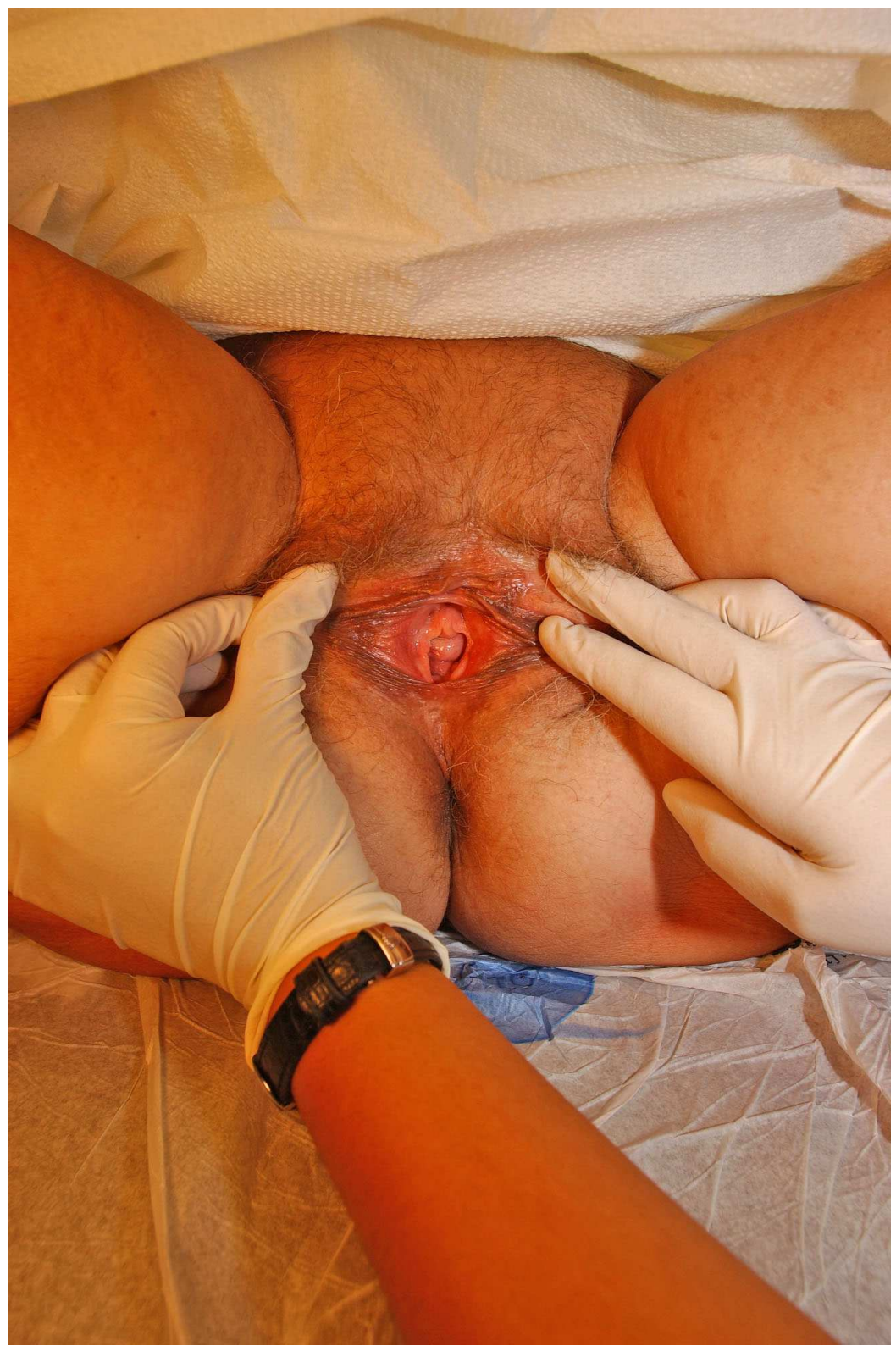

Fig. 2. Figure 1 patient five years after her sacrocolpopexy with no recurrent prolapse. 
The high rates of failed pelvic organ prolapse surgeries have led to a long history of new surgical procedural development. The Frenchman, Dr. Ameline [Ameline, 1957] first published abdominal sacrocolpopexy in 1957 while in the United States, Dr. Lane [Lane, 1962] published a series of four patients undergoing abdominal sacrocolpopexy in the Journal of Obstetrics and Gynecology. Abdominal Sacrocolpopexy entails an extensive abdominal procedure that has potential complications of mesh exposure, hemorrhage, dyspareunia, injury to bladder or ureter and prolapse recurrence. Newer approaches such as laparoscopic and robotic-assisted sacrocolpopexy have proven short-term benefits of expedited convalescence and reduced morbidity; disadvantages, however, are that the procedure is less accessible, higher in cost, and still with no results approaching ten years. [Gilleran JP, 2010].

A

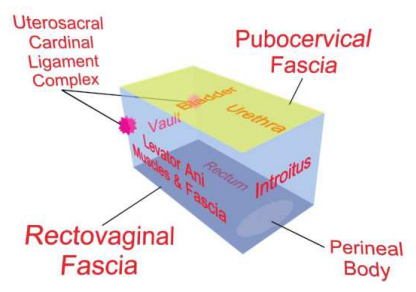

D

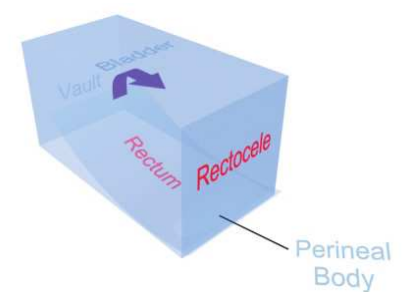

B

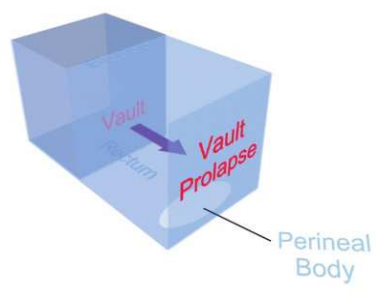

$\mathrm{E}$

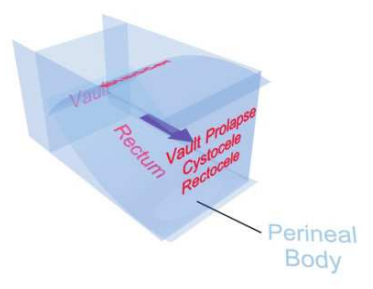

C

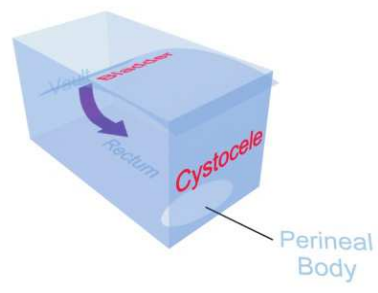

$\mathrm{F}$

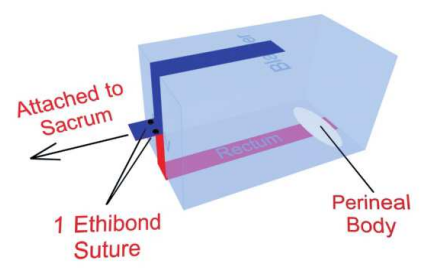

Fig. 1. A. Normal support anatomy of the vagina. B. Vault Prolapse. C. Cystocele D. Rectocele. E. Triple compartment prolapse. F. Anterior and posterior mesh extensions to sacral anterior longitudinal ligament.

\section{Pertinent procedural anatomy}

To perform a sacrocolpopexy, the uterus and cervix need to be excised concomitant with sacrocolpopexy or separately; similar support can be obtained with an intact uterus and cervix by performing a sacrohysteropexy [Lewis, 2011]. Once the uterus is excised, the main supporting structures of the vault, anterior and posterior vaginal walls are three-fold: Uterosacral-cardinal ligament complex [Level One support], Pubocervical/Rectovaginal fascia, and their attachments to the arcus tendineus fascia pelvic and levator ani fascia provide mid-vaginal compartment reinforcement [Level Two support], Levator ani and perineal body [Level Three support] [Figure 1a, Marinkovic \& Stanton 2004]. These three fascial ligament components comprise John Delancey's three autonomous layers of pelvic organ support [Delancey JO, 1992]. The presacral space [Shiozawa, 2010] is the pelvic floor nerve center and has the following anatomic landmark boundaries. Superiorly, we have the lumbosacral intervertebral disc, while with the right pelvic lateral side, we have the right 
common iliac artery/vein and right ureter. On the contralateral pelvic side we have the left common iliac artery/vein and left ureter. The middle presacral area's hallmarks include the middle sacral artery [final branch off the posterior abdominal aorta] and the pelvic plexus, which lie on the medial aspect of the sacrum and can often be seen and venturously prodded. Tread carefully while in this venue because the middle sacral vein develops below the left common iliac vein while draining superiorly into the inferior vena cava and can easily be injured potentiating severe pelvic bleeding. The pelvic venous plexus can in some patients be widely divergent and easily friable to the application of DeBakey or Russian forceps, the gloved-hand, scissors or cautery device and the ensuing brisk, low pressure bleeding is often very difficult to control. When brisk, heavy pelvic plexus bleeding occurs, immediately apply direct digital pressure or a sponge stick to the bleeding vessels. Obtain three units of packed red blood cells into the operating room with visual confirmation of the packed red blood units' physical presence in your room prior to attempting vessel ligature. Once ready, the loss of the least amount of blood and time may be improved by excising a rectangular shape piece of rectus fascia and muscle measuring two by four centimeters, then applying the muscle side directly to the bleeding vessel [Remzi, 2002]. The thrombin within the muscle bed assists in thrombosis along with the applied graft occlusion pressure. Suturing the rectus muscle/fascial graft first with four, interrupted side applied (3-0) polypropylene sutures is recommended. An alternative method is to apply absorbable [Figure 3a, left] copolymer or non-absorbable titanium tacks [Protack, Covidien, Mansfield, MA, USA]. Another prompt and useful method is to directly apply sterile metal thumbtacks with its corequisite applicator [Figure 3b, Hemorrhage Occluder Pin, Tools for Surgery, Stoneybrook, Figure 3b, New York, 11790-2201, USA]. Unfortunately this approach has been less studied [Nivatvongs, 1986].
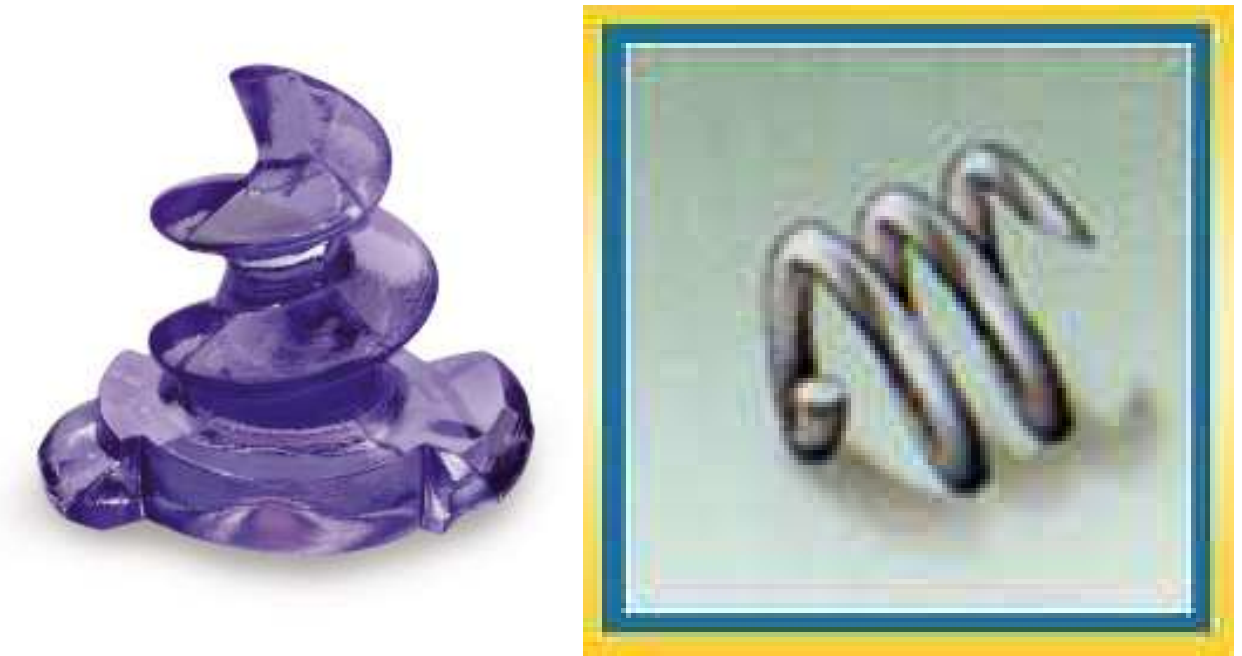

Fig. 3a. [Left] A copolymer delayed absorbable tack [Absorbatack, Covidien, Mansfield, USA] for fixation of polypropylene mesh to the anterior and posterior vaginal walls. [Right] A 5-millimeter titanium tack [Protack, Covidien, Mansfield, USA] for sacral fixation of the polypropylene mesh to the anterior and posterior vaginal walls and/or for the application of a rectus fascia/muscle graft for brisk sacral pelvic plexus venous bleeding. 


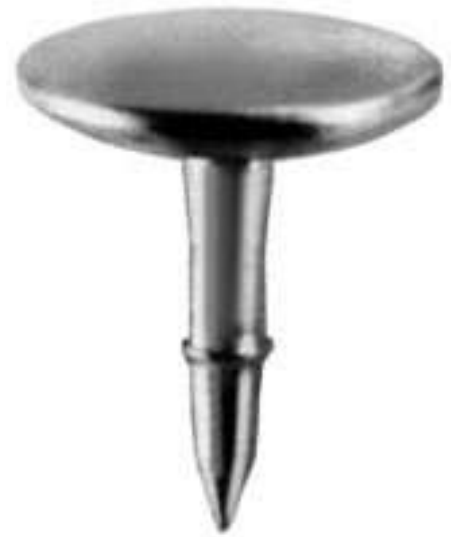

Fig. 3b. A Sterile thumbtack for presacral vascular occlusion

These methods are successful with achieving containment of blood loss in addition to direct closure of the plexus vessel injury. Another important aspect of this procedure is the securing of the double or single $Y$ mesh to the sacrum. The author prefers to perform a suturing or tack fixation of both or singular $\mathrm{Y}$ meshes by loosely fixating each mesh to the sacral anterior longitudinal ligament at the $S_{2}-S_{3}$ level [Marinkovic, 2008]. There is an increased injury risk to pelvic plexus blood vessels but attaining a normal vaginal axis is important to prevent the pelvic floor hyperextension which occurs with sacral promontory fixation and potentially increasing the occurrence of iatrogenic enteroceles and/or rectoceles post-operatively. Surgeon comfort level operating in the presacral space is most important and occurs only through mentorship and experience. Additional manners of fixation have been well described including permanent, delayed absorbable suture, bone anchors or similar absorbable and non-absorbable tacks.

The author recommends a bowel preparation with each patient. This should be initiated the day before and continued with a clear liquid diet and nothing by mouth after midnight the night before surgery. This may enhance landmark anatomical details by debulking the stool content of the sigmoid colon while allowing the surgery to carry on with less circumventing effort. Should an enterotomy occur, mesh must not be utilized at this time [whether or not a bowel preparation has been performed or not] and a reoperation considered in three to six months time. In this short-term, there should be prophylactic antibiotic utilized and a methodical bowel rest with a return to oral intake with the initiation of bowel sounds and the development of flatus.

\section{Preoperative assessment and indications for surgery}

A detailed Pelvic Floor Distress Inventory questionnaire [Teleman 2011] can be utilized to accurately assess patient preoperative and postoperative symptom improvement or worsening over time. Clinical assessment should be multidimensional and performed with observation by the responsible surgeon and staff. The consultation initiates with a detailed history and physical examination. Assessment of prolapse can be performed in the left 
recumbent or lithotomy position although the former may provide a overall assessment for prolapse. The patient should be asked to serially and incrementally cough [or strain] with pronounced inspiration to its maximum capacity, and then hold for three seconds to better gauge the prolapse breadth and width. The author recommends the utilization of the International Continence Society Pelvic Organ Prolapse score [Persu, 2011] for all three compartments and ancillary points of pelvic floor interest. Using a graduated Q-tip with one-centimeter increments on its shaft assists in determining the pelvic organ prolapse score and can be performed ergonomically and in a comfortable setting for both the patient and physician. With indeterminate cases, the patient may be asked to stand and repeat serial, graduated coughs or Valsalva maneuvers while holding for three seconds at their deepest ebb to see the full prominence of the prolapse or stress incontinence episodes. Whether or not the bladder is prefilled, many times patients do not leak with their prolapse reduced in the lithotomy or left lateral recumbent position. Once standing, the patient's stress incontinence may be facilitated. With digitation, the idea is to reduce the prolapse without compressing the bladder neck to avoid closing the bladder neck and iatrogenically causing the recording of a false negative stress test evaluation. Your digit should carefully proceed to the apex of the vault without concomitant applied pressure to either the anterior or posterior vaginal walls. The latter can lead to a false negative enterocele determination. If there is still doubt, you can access with a physiological study to give a dynamic impression of the severity of prolapse and rectal symptoms by utilizing defecography [Steensma, 2007] with corequisite defecation pressure assessment [rectal manometry]. If the dynamic quality of the patient's symptoms is not apparent, we can also utilize Magnetic Resonance Imaging of the Abdomen and Pelvis with intravenous and rectal gadolinium contrast [Groenendijk 2009]. This study can also determine whether hydronephrosis is apparent in which case a pessary should be placed and renal function assessed. Additionally, to better determine preoperative bladder characteristics, multichannel urodynamics [Mueller, 2007] may also be performed with and without their prolapse reduced [with prolapse unreduced -to assess current condition and perhaps bladder urgency while with the prolapse reduced to assess the bladder's post-operative function] to accurately determine the urethral pressure profile and videourodynamics which may become useful with Stage Three or more prolapse of any one compartment.

The bladder has an associated potential for urethral kinking and/or urethral obstruction from urethral hypermobility, cystocele, rectocele/enterocele or prolapsed uterus. In the latter, contrast can be placed into the apex of the vault or into the rectum simultaneously to access the pelvic floor rectal dynamics and with the fluoroscopy arm positioned laterally or in the anterior/posterior position.

Indications for surgery are controversial and are not clearly defined and keen individual patient assessment is important. A useful guide is symptomatic Stage Two or more prolapse patients and potentially all asymptomatic Stage Three or more prolapsed compartments may be successfully managed with the sacrocolpopexy approach. Patients always need to be reminded that pelvic organ prolapse is a systemic disease with a multitude of causative factors including pelvic floor collagen and elastin processing inequities and with several analogous determinant causes, so no surgery can ever be expected to be a one hundred percent symptom remedy. 
- Classification of Synthetic Meshes (Amid, 1997)

- Type 1: Totally macroporous

- $\quad$ Pore size $>75 \mu$

$\begin{aligned} & - \text { PROLENE } \\ - & \text { GYNEMESH PS } \\ - & \text { GYNECARE TVT } \\ - & \text { SPARC }\end{aligned}$

- Type 2: Totally microporous

- $\quad$ Pore size $<10 \mu$

\section{- GORETEX}

- Type 3: Macroporous with multifilaments or microporous component

$\begin{array}{ll}\text { - } & \text { IVS } \\ \text { - } & \text { URATAPE } \\ \text { - } & \text { SURGIPRO } \\ \text { - } & \text { MERSILENE } \\ \text { - } & \text { PARIETEX }\end{array}$

- Type 4: Submicronic pore size

- $\quad$ Pore size $<1 \mu$

Table 1. Types of Synthetic materials

\section{Types of synthetic materials for prolapse support and potential infections}

There are four types of material utilized for pelvic organ prolapse surgery, each varying in their potential contributions to pelvic floor reconstructive surgery. Dr. Amid [Amid, 1997] initiated the classification of synthetic materials for inguinal and abdominal herniorrhaphys in 1997 and system is still in use to better understand macroporous and microporous operative mesh characteristics.

Type 1 macroporous synthetic materials [Ostergard, 2010] have a pore size greater than 75 microns allowing white blood cells [diameter of 7-20 microns] to penetrate through and fight infection and their leukotriene by-products. They also allow for substantial collagen and elastin ingrowth allowing the material to act as supportive platform. Type 2 (microporous mesh) materials have a much smaller pore size diameter of less than 10 microns making it improbable for larger white blood cells to penetrate the material's interstices to combat an infection and its harmful by-products. Collagen and elastin ingrowth may also be impeded. Type 3 mesh materials demonstrate a combination of both Type 1 and Type 2 material properties and because of the type 2 microporous elements the host defenses against infection can be compromised making treatment more difficult and likely less successful with mesh infections. Type 2, 3 and 4 with their submicroporous may make their molecular properties a concern by potentially impairing the host defense mechanisms. Understanding these basic principles is important because mesh infections with Types 2, 3, and 4 materials may necessitate a shorter tolerance with signs and symptoms of mesh infections in lieu of surgery to remove the entire mesh system. Although all four types of mesh have been utilized in sacrocolpopexy, it appears that Type 1 Polypropylene in particular has a manageable incidence of infection. Once the decision to remove an infected piece of mesh has been made the entire material contents. [Finding the original operative report or speaking to the original surgeon is paramount to practicing 
meticulous surgical care]. If a Type 1 mesh infection is suspected, treatment with antibiotics can be pursued and the patient's improvement monitored. Once the mesh has been removed we should wait at least three to six months prior to placement of another synthetic material. The most common bacteria [Falagas, 2004] encountered in both my literature search and Female Reconstructive Surgery practice have been Staphylococcus, Streptococcus subtypes, and Pseudomonas. Treatment should be initiated with a third generation cephalosporin and aminoglycoside. Consideration for not using a third generation penicillin or cephalosporin because of a penicillin allergy may be successfully treated by the substitution of Vancomycin with the continuation of an aminoglycoside. It is equally pertinent to closely monitor aminoglycode peaks and trough levels unless a single aminoglycoside QD dosing regimen is implemented, serial white counts with differential analysis, while blood and infection site cultures with sensitivities are necessary. If the infection is not improving, remember to consider performing a flexible cystoscopy and/or anoscopy to establish whether mesh organ erosion into the bladder or rectum has occurred. If the latter is evident, a consultation with a general or colorectal surgeon is recommended.

\section{Description of the open surgical approach and complications}

To decrease the intrusion of the sigmoid colon contents into the operative field, a bowel preparation with polyethylene glycol-electrolyte solution [Golytely, Braintree laboratories, Braintree, MA 02185, USA] one gallon administered with a clear liquid diet the day before surgery with nothing by mouth after midnight the night before surgery. Bowel preparations with antibiotics have been utilized including a Nichols bowel preparation [Nichols, 1973] with oral neomycin and erythromycin, but these are not encouraged, recommended or, necessary. Intravenous antibiotics are administered in preoperative holding one hour prior to the incision continued for a minimum of twenty-four hours postoperatively. Afterwards the patient is switched to an oral quinolone like Ciprofloxin $500 \mathrm{mg}$ po twice daily, then sent home on the same for an additional ten days. The patient is placed in modified lithotomy position in Allen stirrups. Ample space is created between the patient's legs because an assistant is soon needed once the peritoneum is opened to place within the vagina a large bore disposable number 25 EEA sizer [Autosuture, Covidien, Mansfield, MA, USA]. The EEA sizer helps to define the edges of the vaginal vault, bladder and perineal body facilitating future suture or absorbable tack placement. A Bookwalter retractor will be needed for abdominal compartmentalization of the small and large bowels. The abdominal incision is approached with either a eight to ten-centimeter Phannenstiel incision or a subumbilical vertical incision. The rectus fascia is incised and the superior and inferior rectus fascial flaps are created so their closure is easily performed with one-two centimeters rectal fascial bites. The midline is found with the Metzenbaum scissors by gently opening the Metzenbaum and placing your dominant finger through the incision until the opening in the peritoneum is palpated and subsequently extended both superiorly and inferiorly. Care needs to be taken and this point in time to minimize the opportunity for the creation of an enterotomy or more likely, a cystotomy. An enterotomy should be closed with running 3-0 monofilament suture then Lembertized over the top of the closure with the same type suture this approach is also repeated for cystotomies. The Bookwalter retractor [Codman, Johnson and Johnson, Raynham, MA 02767] is placed for retraction of the sigmoid colon to the patient's left side [closest to the lead surgeon] and with a Kelly retractor blade (two inch by six inch) attached to the Bookwalter with a bowel facing wet lap. The midline abdominal 
contents are held with a Balfour retractor blade. Each Bookwalter blade should be set to use with a bowel facing wet lap to protect the bowel and surrounding blood vessels from iatrogenic injury. A bladder blade is placed on the circular ring (an oval ring for the Bookwalter is utilized for patients with Body Mass Index greater than thirty-five while a two-part circular ring is used for patients with a Body Mass Index less than thirty-four) to retract the bladder caudally and away from the vault and bladder clearly exposing the commonly atretic and weak anterior vaginal wall [Figure 4]. We first approach the placement of the large disposable EEA sizer one inch into the vagina to clearly demarcate the perineal body and distal posterior vaginal wall. We carefully use a Finochetti needle driver with 0 Delayed absorbable [PDS, polydioxanone, Ethicon, Somerset, New Jersey, USA] suture or 0 monofilament permanent suture Polypropylene [Ethicon, Somerville, New Jersey, USA]. The suture is placed once through the right and another suture through the left sides of the perineal body without removing the suture's needle. A hemostat is placed over the needle and the hemostat placed on the outer edge of the Bookwalter retractor. Next, we place the same on the right and left sides up the posterior vaginal every two or three centimeters towards the vault usually for a total of six to eight sutures [two columns of three or four sutures]. Then the posterior mesh consisting of a two inch by twelve inch narrow strip of pre-fabricated and pre-cut Polypropylene mesh [Ethicon, Somerset, New Jersey, USA] has the eight sutures carefully threaded through the top of the mesh and tied on the meshes undersurface [the side facing the bowel]. The authors' concerns for placing the Polyprophylene mesh against the posterior vaginal wall from the onset include that our bite of the posterior vaginal wall may become too compromised and may be too superficial or conversely too deep into the vaginal wall and epithelium. Be mindful that the mesh is

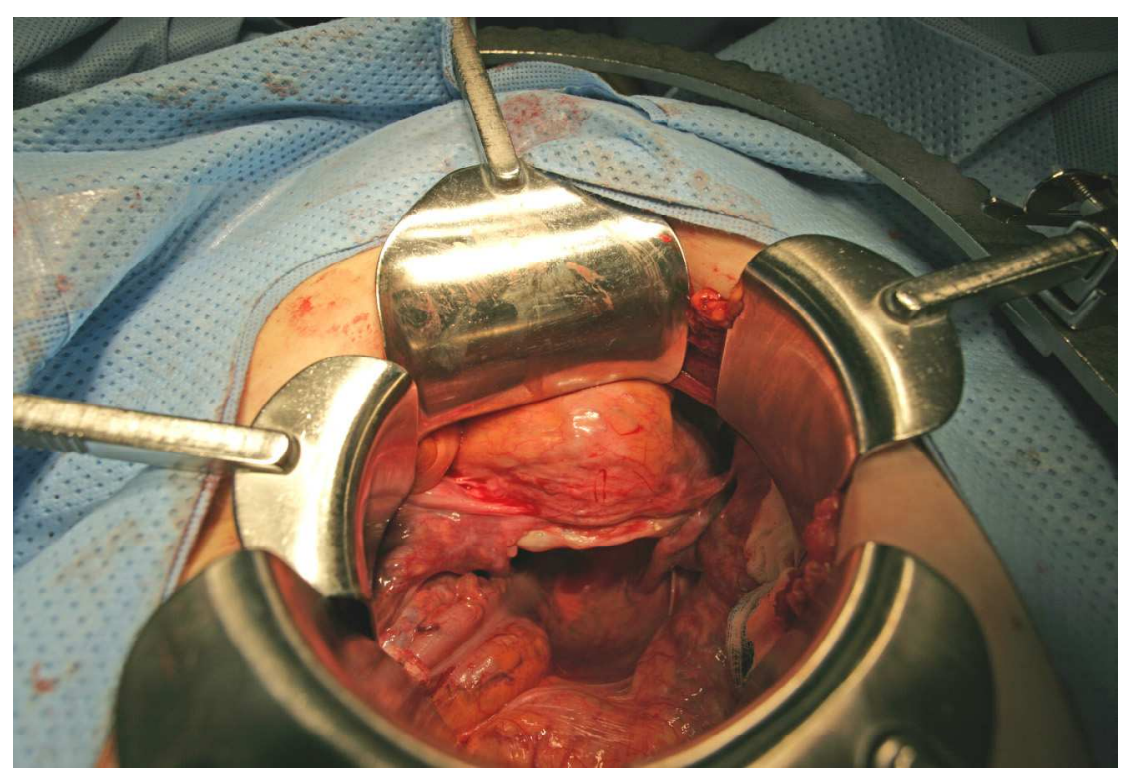

Fig. 4. The Bookwalter retractor has been placed giving us a clear view of the bladder, vault, anterior and posterior vaginal walls. 
also difficult to place a suture through with good control of its depth. This may lead to poor suture fixation and potentially the patient may develop attenuated mesh fixated areas that later succumb to detachment from either vaginal wall and sacral anterior longitudinal ligament. To optimize your suture placement, attempt to get a full bite through the bulk of the vaginal wall first, while not including the epithelium of the vagina. Remember the anterior vaginal wall more commonly attenuated than the posterior vaginal wall and likely more readily pierced through to the vaginal epithelium and may become only apparent with a careful well lit examination during surgery or with colposcopy. Mentally attempt to proceed within two or three millimeters of the vaginal epithelium to prevent a potential suture and/or mesh exposure and accompanying dyspareunia. When starting these cases, performing a concomitant colposcopy with a digital video tower will allow you to see and palpate each individual suture placement to avoid piercing the vaginal epithelium. With gained experience, colposcopy can wait until both meshes have been placed vaginally. Once each suture throw is placed through the mesh, remember that for the posterior mesh, the knots of the suture will be tied onto the bowel facing side of the mesh [side directly facing and juxtaposed to the bowel) as in [Figure 5].

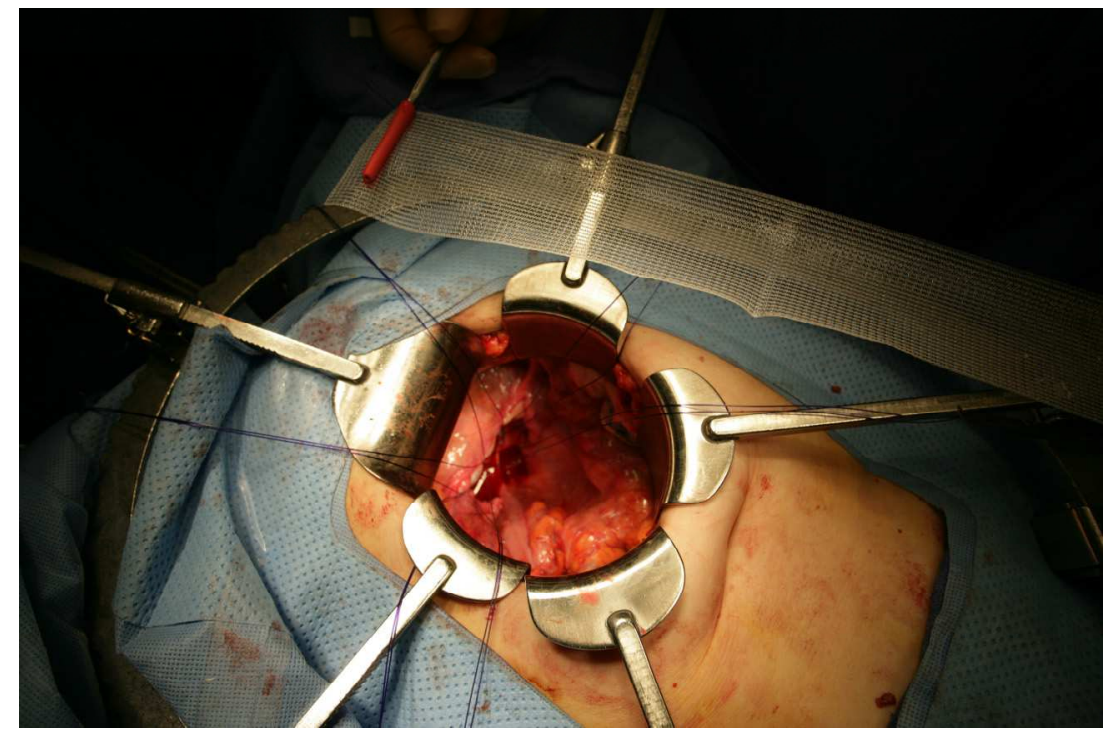

Fig. 5. Represents when the sutures are placed through the posterior vaginal wall and now the sutures are passed from the top of the mesh so the knots are tied on its underside.

Once the sutures have been placed through the mesh in right and left columns, they can be tied from the bottom to the top. If tied from top to bottom, the sutures at the bottom will be more difficult to tie and the mesh will move from one side to the other from the midline. The resulting mesh may not be placed straight but angled to the right or left side instead of straight towards the sacrum. 
Starting with the perineal body [Figure 6] towards the vault is the most ergonomic approach still allowing the surgeon the opportunity to adjust the mesh from side to side as they proceed to maximize a straight and horizontal plane. This same principle can be applied to the anterior mesh.

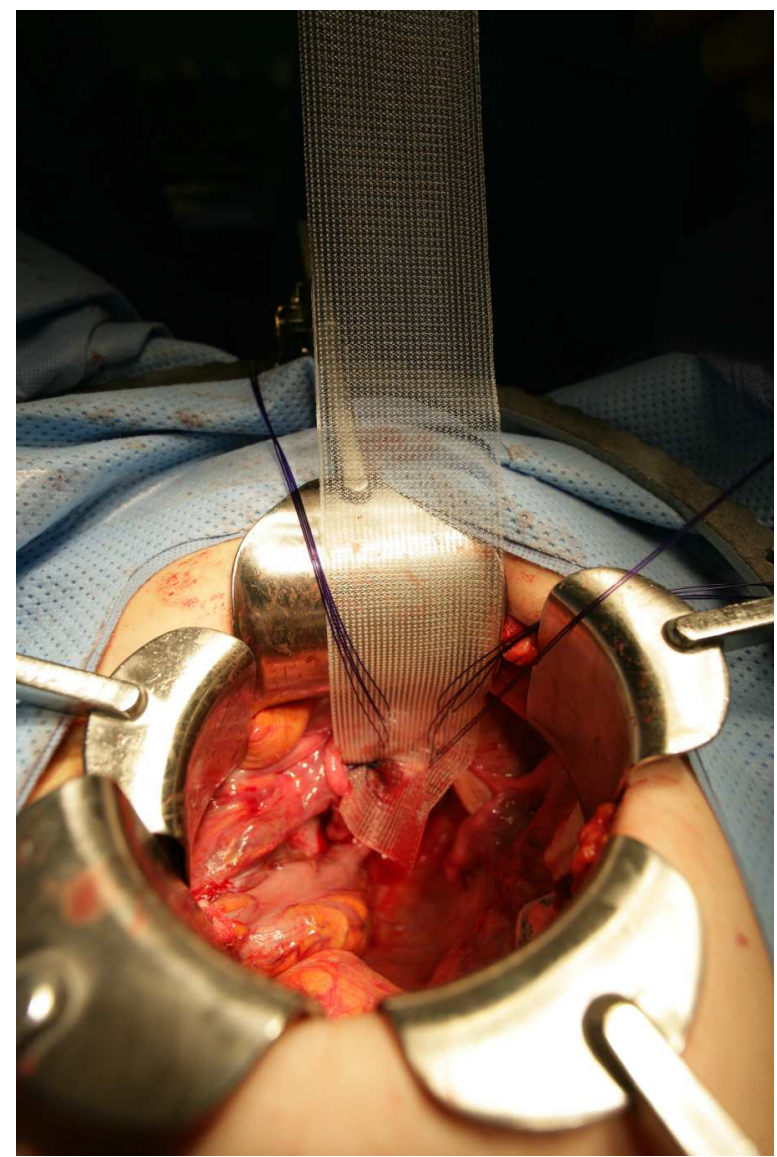

Fig. 6. The perineal body has its two sutures [one right and left sided] and are strung through the mesh and tied. Usually this is not done until all sutures are placed through the posterior vaginal wall then strung through the mesh and tied on the bowel facing side of the Polypropylene mesh.

The anterior mesh is placed on the apical anterior vaginal wall. To better gauge the cephalic aspect of the bladder and prevent cystotomy, the bladder can be filled with two hundred milliliters of indigo carmine. If a cystotomy is made, the dye will venture out and delineate the area in need of closure. Once the surgeon is experienced with mobilization of the bladder off the anterior vaginal wall, the author still recommends that the bladder be filled 
and carefully checked for cystotomies after mobilization is completed. The best time to correct cystotomies is during the case and not post-operatively. We recommend for closure of a cystotomy 2-0 Polyglactin 910 or similar monofilament absorbable suture with the deep layer being a continuous running closure then the more superficial layer with the same Polyglactin 910 suture in a Lembert interrupted fashion. With a cystotomy, the patient should have a 16 F Foley catheter left in place for ten days and a voiding cystourethrogram performed. If there is no leakage, the Foley can be discontinued. If there is still some leakage, leave the Foley in for an additional ten days and repeat the voiding cystourethrogram. Once the case is almost completed and closure initiated, it is recommended to perform a colposcopy with video guidance to ascertain whether there is any vaginal enterotomy or suture/tack penetrating through the vaginal epithelium. If penetration occurs-the suture or tack should be removed and carefully replaced.

Once both meshes have been sutured to both the anterior and posterior vaginal walls, we need to open the sacral peritoneum from the sacral promontory (palpable by hand and three centimeters below the aortic bifurcation) with the electrocautery set at fifteen watts. Cut and coagulate [blend] to minimize potential radiating heat injury to the underlying blood vessels and ureters. The right ureter is also important to visualize and/or palpate to ascertain its pelvic course. [The right or left ureter is most commonly injured with suture when closing both sacral peritoneal flaps during the retroperitonealizing of both meshes to prevent bowel adherence and obstruction. This is ascertained when there is no flow out the right ureter with a cystoscopic examination. Usually untying and removing the multiple interrupted retroperitonealizing sutures will safely restore flow to the affected ureter]. Once we are oriented, we carefully incise the peritoneum from the sacral promontory down to $S_{5}$. Then carefully and methodically cauterize the underlying tissue toward the right side of the sacrum. The normal vaginal axis for vault orientation is towards $S_{3}$. We must always be prepared for rapid venous bleeding when creating the right and left flaps for future retroperitonealizing of both meshes. If rapid bleeding occurs, take long-ring forceps with a sponge tip and apply pressure to the area while asking for three units of packed red blood cells to be held for potential infusion. Long DeBakey forceps are used to hold the bleeding vessel and the electrocautery should be increased to thirty watts. Apply significant electrocautery at least twice before abandoning cautery. The next means can be suture ligation with 4-0 double-edged polypropylene or the author's two favorite alternatives, which may also be quicker and more secure from the beginning. First, a sterile tenmillimeter wide and seven millimeter deep thumbtack can be applied directly into the bleeder or a two inch by three inch rectus fascial graft [preferably not a flap although either can be utilized] is taken from the abdominal incision with its accompanying rectal muscle. Apply the muscle side onto the bleeder first and apply pressure and suture the rectus fascia to the underlying tissue. Any of these four methods should successfully manage rapid bleeding. Another useful alternative is to apply packing with a later return to the operating room and/or to request a radiology vessel embolization.

Alternative methods for mesh attachments to the sacral anterior longitudinal ligament include titanium tacks [Figure 10][Tan-Kim, 2011]. With either method, the mesh needs to be secured loosely to the longitudinal ligament to prevent detachment, since the mesh may contract ten to twenty percent along its longitudinal length over time. After both meshes 


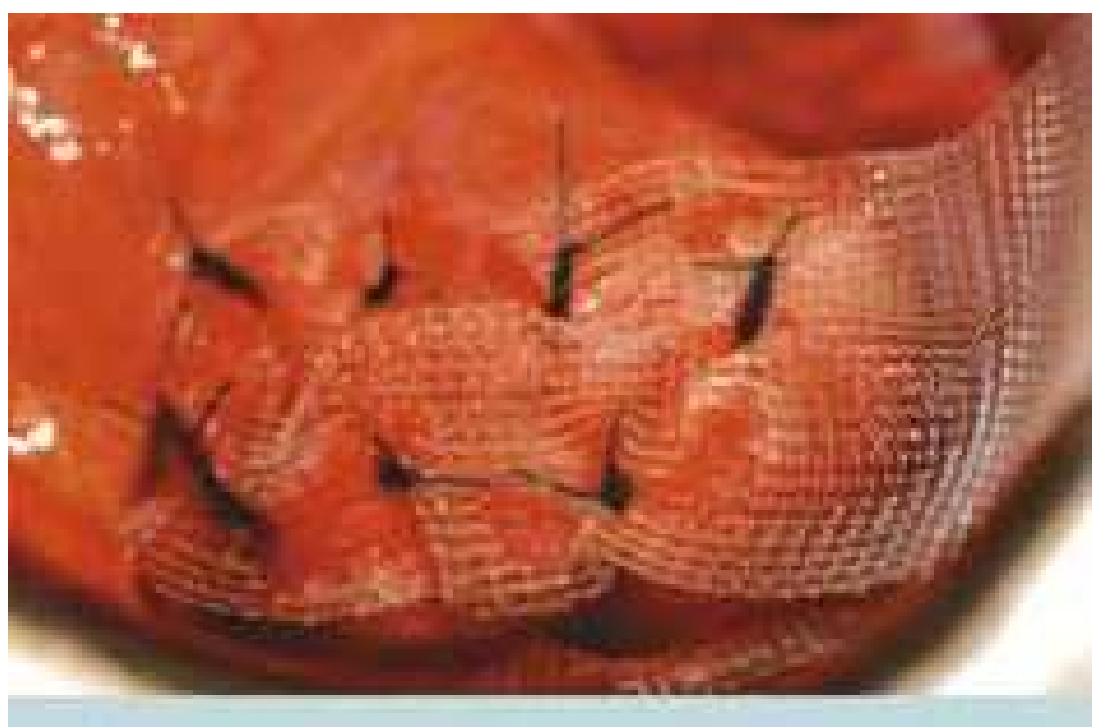

Fig. 7. The bladder has been mobilized two centimeters off the apical vault and the same size polypropylene mesh applied to the anterior vaginal wall with only two columns [right and left] of four sutures for a total of eight sutures on the anterior mesh. In this figure the eighth left top suture has not been placed.

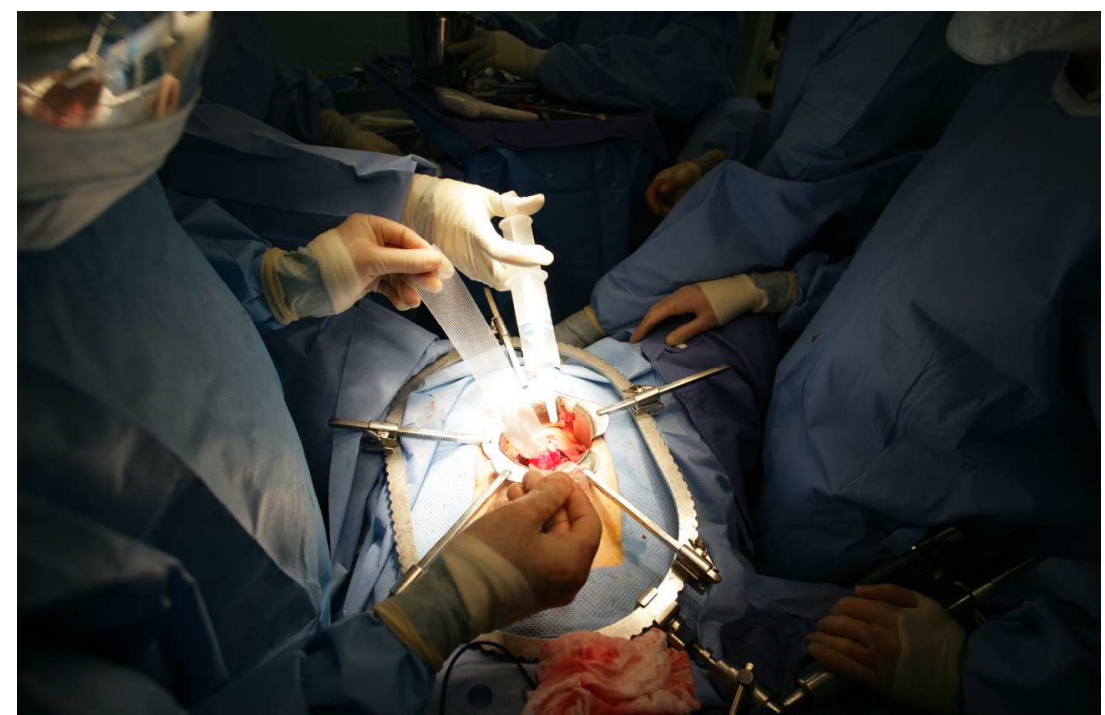

Fig. 8. Both the anterior and posterior meshes have been applied with suture and the sacral peritoneum overlying the sacrum needs to be incised with cautery to allow access to the sacral anterior longitudinal ligament for the anchoring of both meshes. 


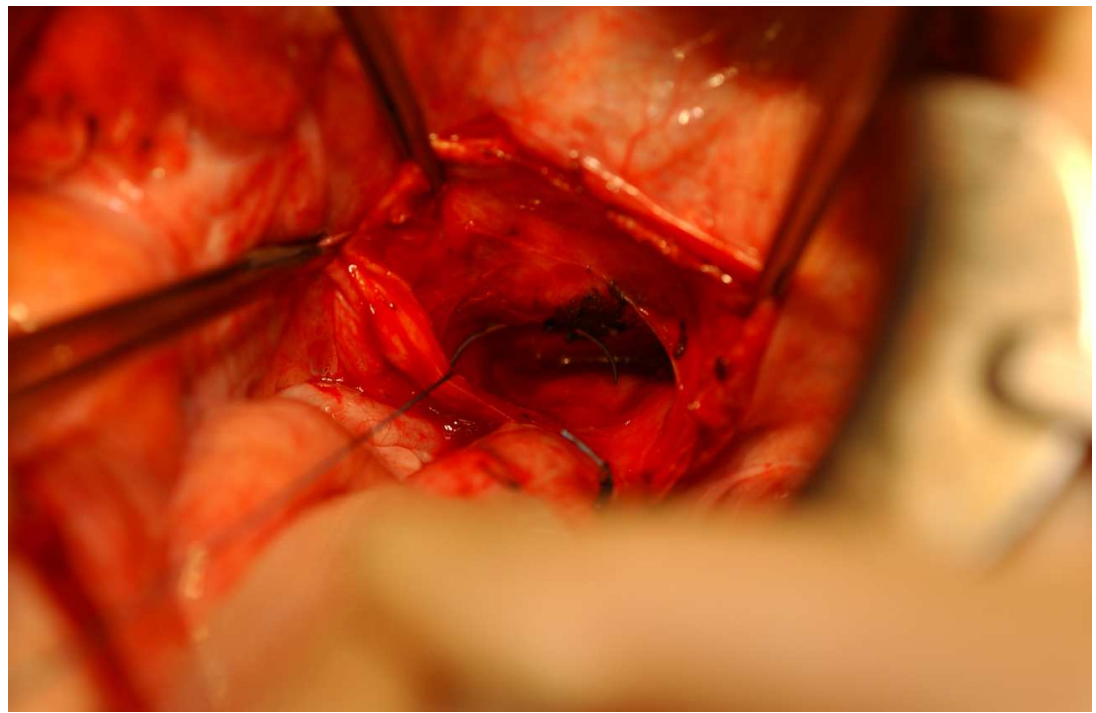

Fig. 9. Both meshes can be anchored to the sacral anterior longitudinal ligament with 0 permanent suture.

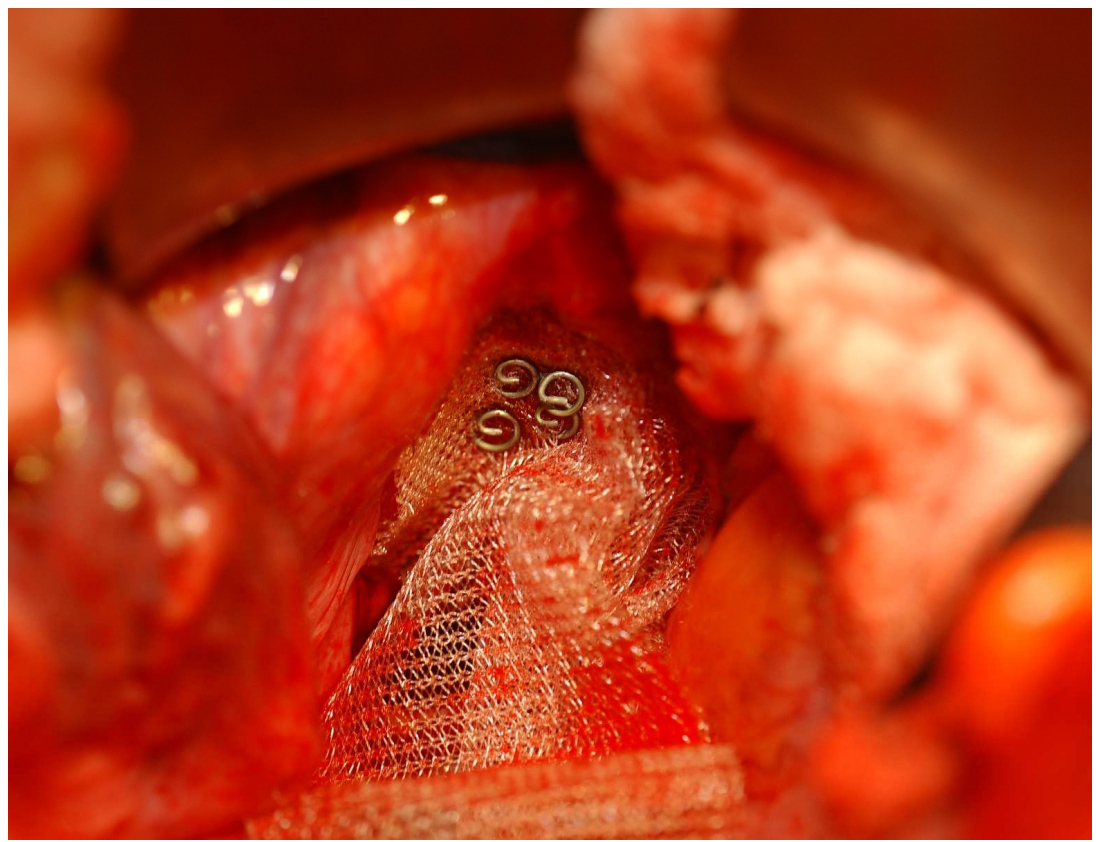

Fig. 10. One alternative sacral fixation method is the use of titanium tacks. Both polypropylene meshes here have been anchored by a series of rectangular oriented titanium tacks [Figure 3a]. 
have been successfully anchored to the sacrum, we must digitally feel some looseness or bend in the middle to prevent detachment or severing of the polypropylene monofilament mesh.

To complete the sacrocolpopexy, close the sacrum peritoneum while retroperitonealizing both meshes [Figure $11 \& 12$ ]. Take the serosa and muscularis of the bladder's most cephalad aspect and attach it to the beginning of your sacral peritoneal incision or directly to the most cephalic aspect of either mesh so the entire length of the either mesh is not exposed to the surrounding small or large bowel for potential obstructive bowel complications. Once closed, the rectus muscle is re-approximated in the midline with running polyglactin 910 suture and the rectus fascia with 0 loop Polydioxanone suture. The subcutaneous area is irrigated to prevent a seroma and both sides are re-approximated with interrupted polyglactin 910 . The skin may be closed with interrupted subcuticular 4-0 chromic sutures followed by a Tegaderm transparent 8 " $\times 2$ 2" dressing. Staples may be used in obese patients

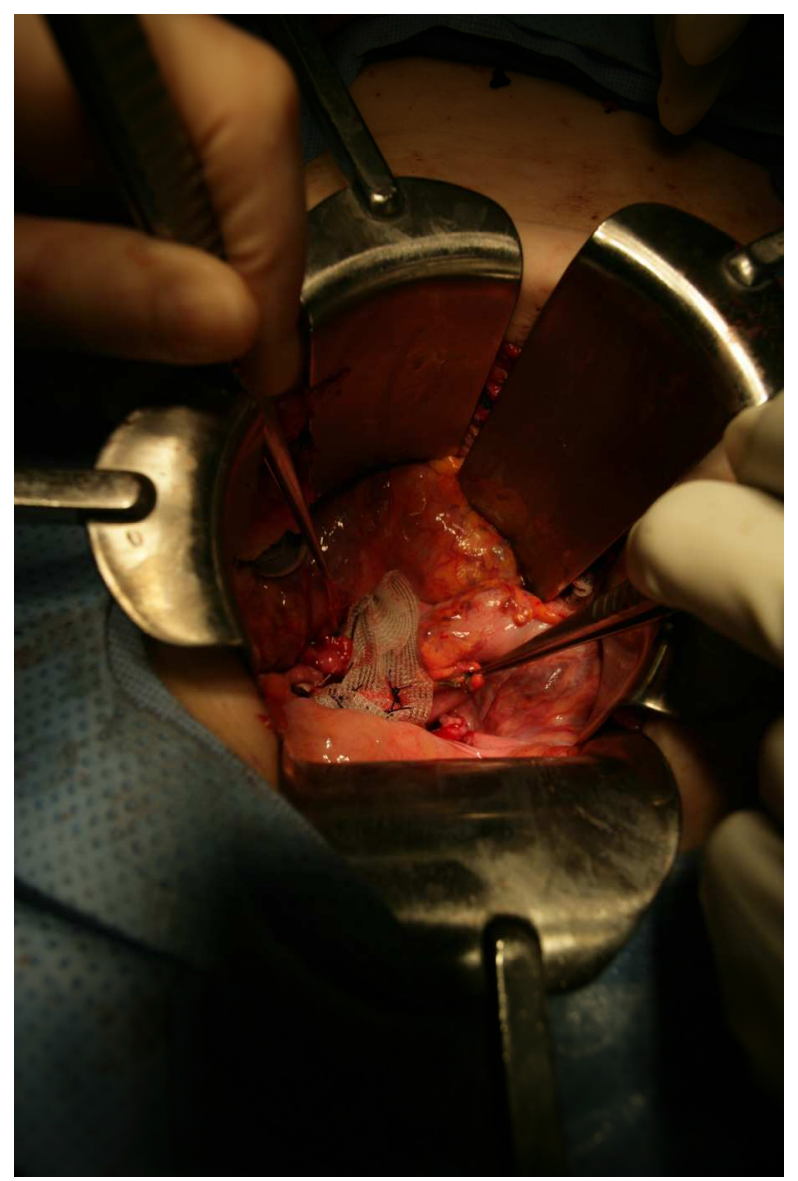

Fig. 11. Both meshes have been secured to the sacral anterior ligament and now the sacral peritoneum flaps are re-approximated. 


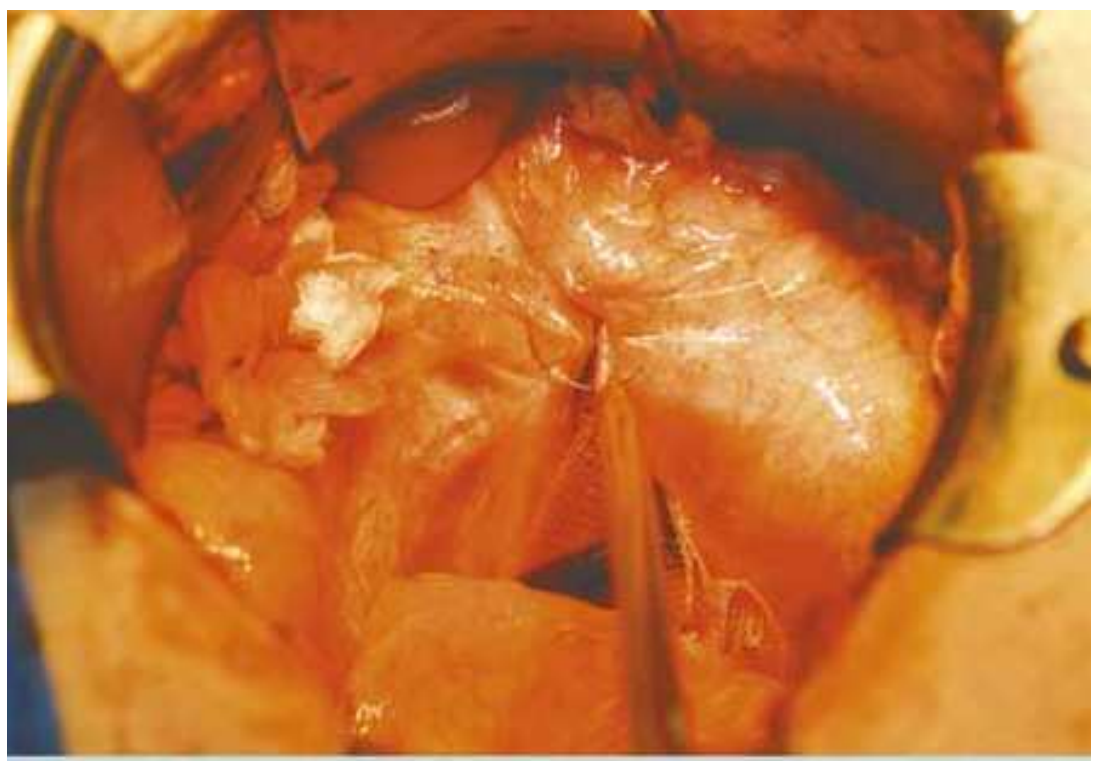

Fig. 12. Both meshes have been closed over their top by the sacral peritoneum. If there is not enough peritoneum to cover both meshes you can use the serosa of the cephalic part of the bladder and suture directly to the sacral peritoneum or to the most cephalic section of visible mesh.

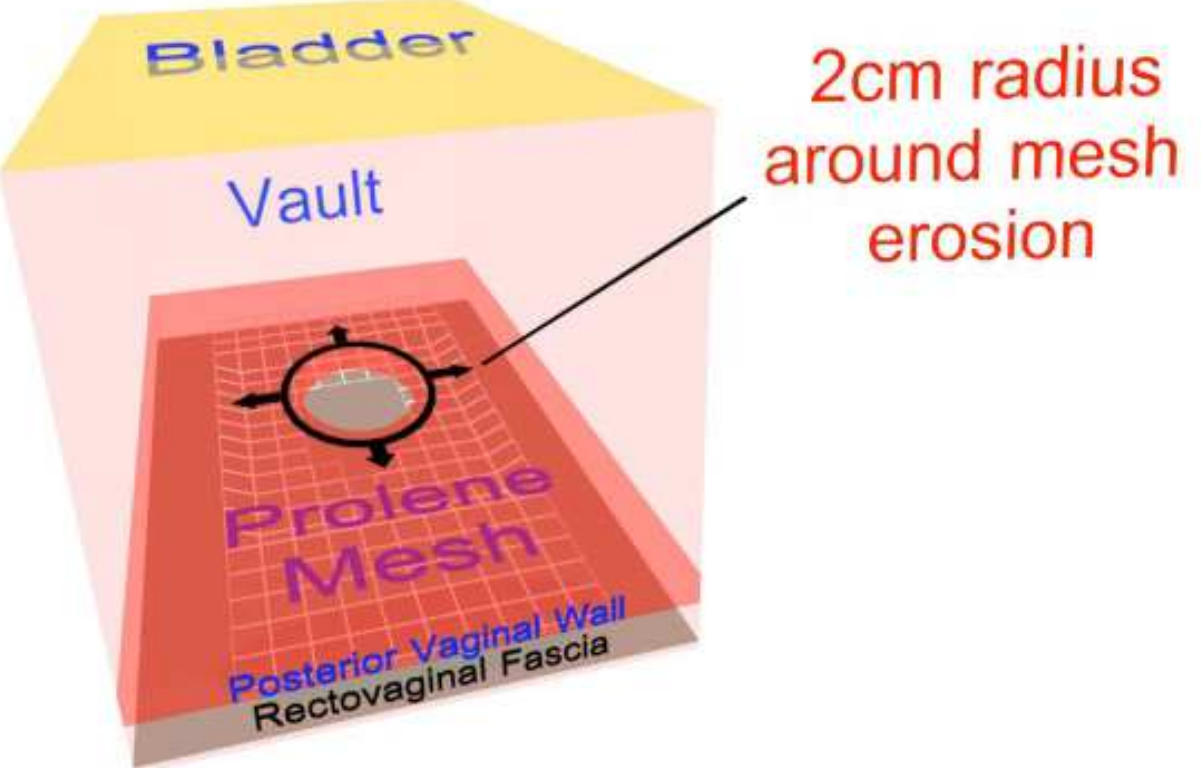

Fig. 13. An illustration of a macroporous mesh exposure through the posterior vaginal wall. 


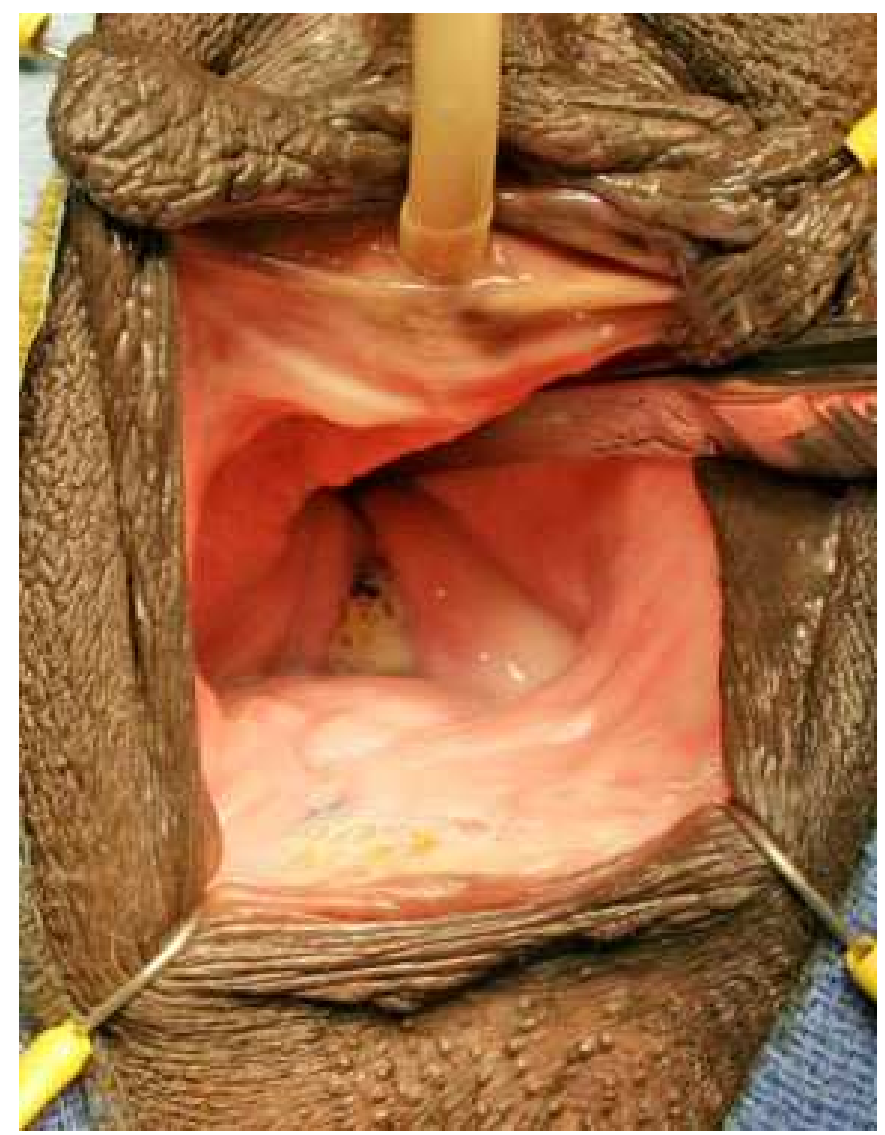

Fig. 14. A Mersilene mesh exposure through the posterior vaginal wall at the perineal body and posteriorly at the vaginal vault.

or those with frail skin. Retention sutures for those at risk by history for fascial dehiscence can also be considered. The usefulness of transparent dressing is the ability and ease of checking the incision by all heath care professionals at all times without having to consistently traumatize the patients with the reapplication and removal of bandages.

\section{Mesh exposure management}

Mesh exposure is an important complication. Rates may range from zero to twenty percent [Skala, 2011] in the first two post-operative years. It can occur with the patient complaining of a rough and painful vaginal area, a draining sinus, or without any symptoms. This is why when mesh is utilized, we need to periodically follow up with the patient. My recommended conservative follow-up course is 6 weeks, 3 months, 6 months, 12 months, 24 months, and 36 months, then as needed thereafter. When examining the patient, the lithotomy position is the standard by which all other examination position's are compared. But always entertain utilizing the left recumbent position which is also very helpful to examine the vaginal walls. If 


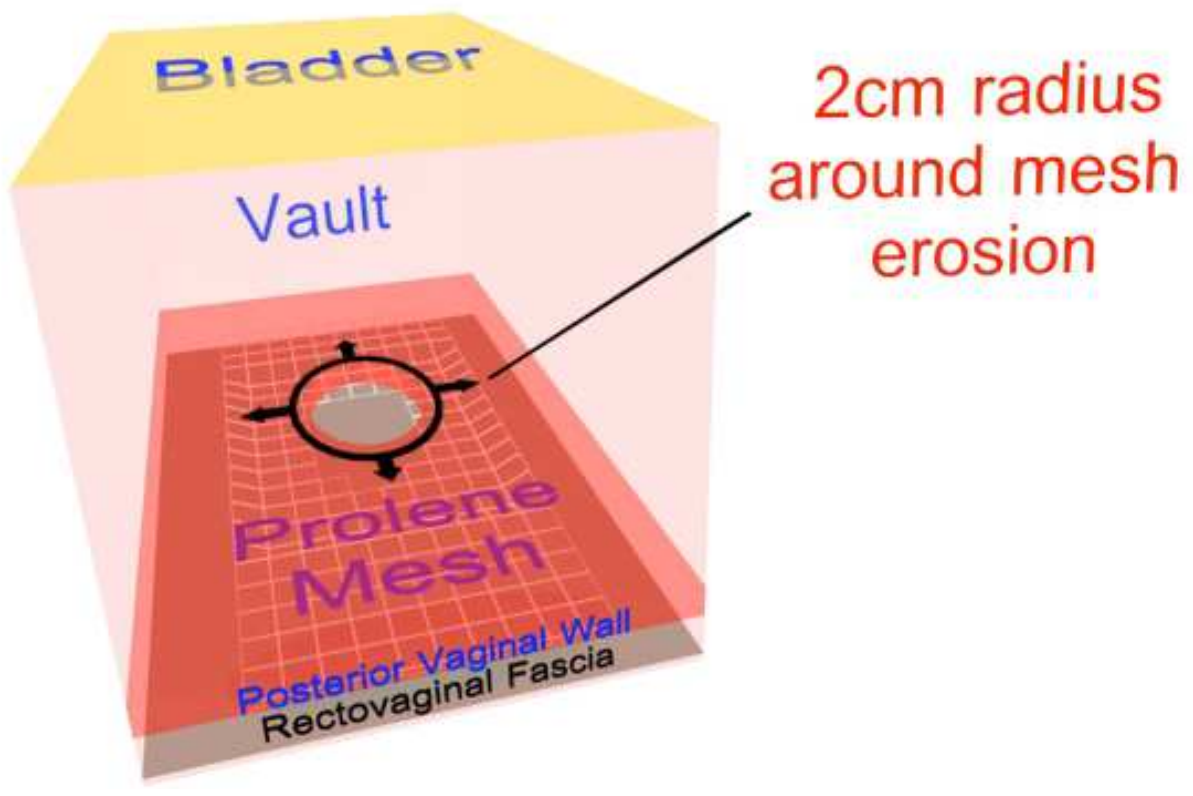

Fig. 15. The first step in this repair is to grasp the mesh with an Alice clamp and circumscribe a two-centimeter perimeter around the mesh exposure. Then excise the protruding mesh with the Metsenbaum scissors. The right and left edges should be undermined with scissors for an additional one to two centimeter's circumferentially then closed with a tension free approach utilizing a deep running layer with 3-0 Polyglactin 910. Followed by a superficial Lembertizing layer with interrupted monofilament.

readily available, colposcopy is also a useful office procedure to ascertain early supple and pre-exposure development or signs of mesh infection that may be missed on a standard physical examination. I recommend that all post sacrocolpopexy patients have a colposcopy at least once post-operatively and as needed thereafter. When an exposure has surfaced during your examination some aspects are important to note and guide your treatment. If the exposure size when measured with a malleable ruler or a graduated Q-tip is less than one centimeter or involves two or less areas of this size, it may be amenable to apply estrogen cream for six weeks and then schedule a follow-up re-examination. If it has not been re-epithelized, consideration for outpatient surgery should be entertained. If exposures are more than one centimeter and/or are located in two or more analogous locations this correction should be performed in the operating room. Two or more areas of concern may foreshadow a seriously thin operative flap problem, erosion, or infection.

Repairs need to be performed with a two centimeter, circumferential, mesh mobilization and excision followed by in a deep continuous closure followed by a superficial interrupted Lembertizing layer closure with 3-0 polyglactin 910. A Lembert closure approach embodies an incisional closure initiating with a deep continuous closure followed by a superficial interrupted closure of the same incision. For the latter, the surgeon starts at the beginning of the incision and goes through the area five millimeters lateral to the right and left sides of 
the incision and buries the original incision within this superficial interrupted suture line. This approach affords the closure with a good-healing tissue process.

The important point is to make the closure tension free and if the incision is close to the introitus to cut your sutures long to prevent the patient feeling a sticking sensation from the tips of the short suture when they are sitting. New monofilament antibacterial-coated [poliglecaprone 25 plus] suture is available that may add infection assistance with these closures.

\section{Conclusion}

Sacrocolpopexy is an effective option for the correction of advanced pelvic organ prolapse and can be performed in either one of three manners including open, laparoscopy and robotassisted approaches. Its major advantage is that it has a greater than ten-year success rate and a fifty year history of experience in the control of pelvic organ prolapse. Sacrocolpopexy may be more enduring than a vaginal approach and for the sexually active patient provides the longest possible vaginal length. Currently many of the common complications are amenable to medical or surgical therapy usually as an outpatient visit or same-day surgery.

\section{References}

Ameline A, Huguier J. La suspension posterieure aux disques lombo-sacres: technique de remplacement des ligaments utero-sacres par voie abdominale. J Gynecol Obstet Biol Reprod 1957; 56:94-99.

Amid, PK. Classification of biomaterials and their related complications in abdominal wall hernia surgery. Hernia 1997 1:15-21.

Connell, KA. Elastogenesis in the vaginal wall and pelvic organ prolapse. N Engl J Med 2011 Jun16; 364(24): 2356-2358.

Delancey JO. Anatomic aspects of vaginal eversion after hysterectomy. Am J. Obstet Gynecol 1992 Jun; 166:1717-1724.

Falagas ME, Kasiakou SK. Mesh-related infections after hernia repair surgery. Clin Microbiol Infect 2005; 11:3-8.

Gilleran JP, Johnson M, Hundley A. Robotic-assisted laparoscopic mesh sacrocolpopexy. Ther Adv Urol 2010; 2(5): 195-208.

Groenendijk AG, Birnie E, de Blok S, Adriaanse AH, Ankum WM, Roovers JP, Bonsel GJ. Clinical decision taking in primary pelvic organ prolapse; the effects of diagnostic tests on treatment selection in comparison with a consensus meeting. Int Urogynecol J Pelvic Floor Dysfunct 2009 Jun; 20(6): 711-719.

Lane, F.E. Repair of post hysterectomy vaginal vault prolapse. Obstet Gynecol(1962) 20: 72 77.

Lewis CM, Culligan P. Sacrohysteropexy followed by successful pregnancy and eventual reoperation for prolapse. Int Urogynecol J 2011; PMID 22179338.

Maher C, Feiner B, Baessler K, Adams EJ, Hagen S, Glazener CM. Surgical management of pelvic organ prolapse in women. Cochrane Database Syst Rev 2010 Apr 14;(4): CD004014. 
Marinkovic SP. Will hysterectomy at the time of sacrocolpopexy increase the rate of polypropylene mesh erosion? Int Urogynecol J Pelvic Floor Dysfunction 2008 Feb; 19(2): 199-203.

Mainkovic SP, Stanton SL. Incontinence and voiding difficulties associated with prolapse. J Urol 2004 Mar; 171(3): 1021-1028.

Mueller ER, Kenton K, Mahajan S, FitzGerald MP, Brubaker L. Urodynamic prolapse reduction alters urethral pressure but not filling or pressure flow parameters. J Urol 2007 Feb; 177(2): 600-603.

Nichols RL, Broido P, Condon RE, Gorbach SL, Nyhus LM. Effect of preoperative neomycinerythromycin intestinal preparation on the incidence of infectious complications following colon surgery. Ann Surg 1973 October; 178(4): 453-462.

Nivatvongs S, Fang DT. The use of thumbtacks to stop massive presacral hemorrhage. Dis Colon Rectum 1986; 29(9): 589-590.

Olsen AL, Smith VJ, Bergstrom JO, et al. Epidemiology of surgically managed pelvic organ prolapse and urinary incontinence. Obstet Gynecol. 1997; 89(4): 501-506. doi: 10.1016/S0029-7844 (97) 00058-6.

Ostergard DR. Vaginal mesh grafts and the food and drug administration. Int Urogynecol J pelvic Floor Dysfunction 2010 October; 21(10): 1181-1183.

Persu C, Chapple CR, Cauni V, Gutue S, Geavlete P. Pelvic organ prolapse quantification system (POP-Q)- a new era in pelvic prolapse staging. J Med Life 2011 Jan-Mar; 4(1): 75-81.

Remzi, FH, Oncel M, Fazio VW. Muscle tamponade to control presacral venous bleeding: report of two cases. Dis Colon Rectum 2002; 45(8): 1109-1111.

Scali P, Blondon J, Bethoux A, Gerard M. Les operations de soutenement suspension par voie haute dans le traitement des prolapsus vaginaux.J Gynecol Obstet Biol Reprod. 1974; 3:365-378.

Shiozawa T, Huebner M, Hirt B, Wallwiener D, Reisenauer C. Nerve-preserving sacrocolpopexy: anatomical study and surgical approach. Eur J Obstst Gynecol Reprod Biol 2010 Sep; 152(1): 103-107.

Skala C, Renezeder K, Albrich S, Puhl A, Laterza RM, Naumann G, Koelbl H. The IUGA/ICS classification of complications of prosthesis and graft insertion: a comparative experience in incontinence and prolapse surgery. Int Urogynecol 2011 PMID 21789657.

Steensma AB, Oom DMJ, Burger CW, Schouten WR. Comparison of defecography and $3 \mathrm{D} / 4 \mathrm{D}$ translabial ultrasound in patients with pelvic organ prolapse and/or evacuation disorders. Ultrasound in Ob/Gynecol 2007; 30:447.

Subak LL, Waetjen LE, Eeden S, et al. Cost of pelvic organ prolapse surgery in the United States.Obstet Gynecol. 2001; 98:646-651. Doi: 10.1016/S0029-7844 (01) 01472-7.

Tan-Kim J, Menefee SA, Luber KM, Nager CW, Lukacz ES. Prevalence and risk factors for mesh erosion after laparascopic -assisted sacrocolpopexy. Int Urogynecol J Pelvic Floor Dysfunct 2011 Feb; 22(2): 205-212.

Teleman P, Stenzelius K, Lorizzo L, Jakobsson U. Validation of the Swedish short forms of the pelvic floor impact questionnaire (PFIQ-7), pelvic floor distress inventory (PFDI-20) and pelvic organ prolapse/urinary incontinence sexual questionnaire (PISQ-12). Acta Obstetricia et Gynecologica Scan 2011; 90(5): 483-487. 


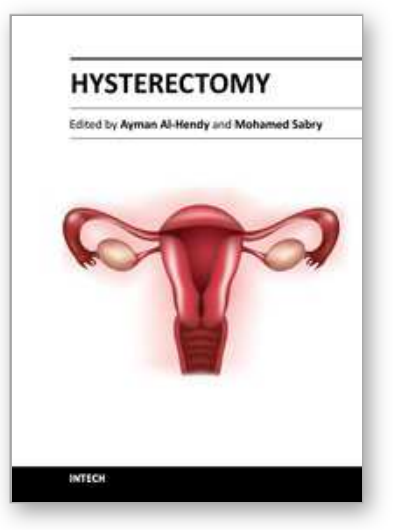

\author{
Hysterectomy \\ Edited by Dr. Ayman Al-Hendy
}

ISBN 978-953-51-0434-6

Hard cover, 426 pages

Publisher InTech

Published online 20, April, 2012

Published in print edition April, 2012

This book is intended for the general and family practitioners, as well as for gynecologists, specialists in gynecological surgery, general surgeons, urologists and all other surgical specialists that perform procedures in or around the female pelvis, in addition to intensives and all other specialities and health care professionals who care for women before, during or after hysterectomy. The aim of this book is to review the recent achievements of the research community regarding the field of gynecologic surgery and hysterectomy as well as highlight future directions and where this field is heading. While no single volume can adequately cover the diversity of issues and facets in relation to such a common and important procedure such as hysterectomy, this book will attempt to address the pivotal topics especially in regards to safety, risk management as well as pre- and post-operative care.

\title{
How to reference
}

In order to correctly reference this scholarly work, feel free to copy and paste the following:

Serge P. Marinkovic, Lisa M. Gillin and Christina M. Marinkovic (2012). Sacrocolpopexy for Post Hysterectomy Vault Prolapse, Hysterectomy, Dr. Ayman Al-Hendy (Ed.), ISBN: 978-953-51-0434-6, InTech, Available from: http://www.intechopen.com/books/hysterectomy/sacrocolpopexy-for-post-hysterectomy-vault-prolapse

\section{INTECH}

open science | open minds

\section{InTech Europe}

University Campus STeP Ri

Slavka Krautzeka 83/A

51000 Rijeka, Croatia

Phone: +385 (51) 770447

Fax: +385 (51) 686166

www.intechopen.com

\section{InTech China}

Unit 405, Office Block, Hotel Equatorial Shanghai

No.65, Yan An Road (West), Shanghai, 200040, China

中国上海市延安西路65号上海国际贵都大饭店办公楼405单元

Phone: +86-21-62489820

Fax: +86-21-62489821 
(C) 2012 The Author(s). Licensee IntechOpen. This is an open access article distributed under the terms of the Creative Commons Attribution 3.0 License, which permits unrestricted use, distribution, and reproduction in any medium, provided the original work is properly cited. 